International Journal of Instruction e-ISSN: 1308-1470 • www.e-iji.net
July $2019 \bullet$ Vol.12, No.3

p-ISSN: 1694-609X

pp. 459-480

Received: 02/12/2018

Revision: 09/04/2019

Accepted: 12/04/2019

OnlineFirst:10/05/2019

\title{
Flipped vs. Unplugged Instructions: Sailing EFL Learners' Oral Proficiency through Virtual and Real Learning Communities
}

\section{Elahe Solimani}

Department of English Language, Isfahan (Khorasgan) Branch, Islamic Azad University, Isfahan, Iran, e.solimanie@gmail.com

\section{Ahmad Ameri-Golestan}

Department of English, Majlesi Branch, Islamic Azad University, Isfahan, Iran, a.ameri@iaumajlesi.ac.ir

\section{Ahmadreza Lotfi}

Department of English Language, Isfahan (Khorasgan) Branch, Islamic Azad University, Isfahan, Iran, lotfi.ahmadreza@gmail.com

This study sought to probe the effect of two non-conventional instructions namely Flipped Classroom Model (FCM) vs. Unplugged Classroom Model (UCM) on Iranian EFL learners' oral proficiency. Therefore, 90 upper-intermediates were randomly assigned to two experimental groups and one control group (30 each). The FCM and UCM participants were equipped with WhatsApp online platform and conversation-driven, emergent-based instructions respectively. Their counterparts in control group received textbook instruction. After four weeks of instruction, learners' performances were evaluated using a mixed method design with interviews and paper-based exams' posttests besides the Community of Inquiry (CoI) questionnaire and the instructor's observations for the nonconventional classrooms. The results indicated that both FCM and UCM instructions were successfully implemented for promoting learners' oral proficiency. However, learners reported divergent perspectives that may help the EFL teachers to develop FCM and UCM not only for enhancing oral proficiency but also for expanding learners' problem-solving techniques.

Keywords: flipped classroom model, unplugged classroom model, community of inquiry, oral proficiency, non-conventional instruction

\section{INTRODUCTION}

Recent thrust of research is stressing the adoption of a praxis in which teachers have leeway to convey the message to the learners as they find it more appropriate. In other

Citation: Solimani, E., Ameri-Golestan, A., \& Lotfi, A. (2019). Flipped vs. Unplugged Instructions: Sailing EFL Learners' Oral Proficiency through Virtual and Real Learning Communities. International Journal of Instruction, 12(3), 459-480. https://doi.org/10.29333/iji.2019.12328a 
words, textbooks are not supposed to hinder the process of teaching. This notion has led to the emerging of some nonconventional methods, such as unplugged and flipped classrooms (Meddings \& Thornbury, 2009; Zhang, 2016; Wu, Hsieh \& Yang, 2017). The concept of "flipped learning" is based on pedagogical practices in online platforms which engages learners in gadget-based learning outside the classroom and motivates learners to communicate without any fear of being judged by other peers and also by the teacher (Hung, 2017; Zhai, Gu, Liu, Liang \& Tsai, 2017). It is a widely held view that learning a language is in the same vain with gaining mastery over that language and according to many in the field mastery implies being able to speak that language accurately and fluently (Folse, 2006 as cited in Wu, et al., 2017). Regarding the importance of EFL learners' oral proficiency, a considerable amount of literature has also grown up around the theme of light material or even no material with more emphasis on conversation-driven classes based on emergent language. The concept of light material is a dominant feature of "Dogmed ELT" (Thornbury, 2002, 2005; Meddings \& Thornbury, 2009; Thornbury \& Slade, 2006). Later on, Meddings and Thornbury (2009) explained that there are three requisites for making a classroom a real unplugged experience. In other words, "dogme ELT" is a) Conversation-driven, b) materials-light and c) based on emergent language. Care has been placed over the interaction zone in the classroom which is rooted in Vygotsky's (1978) Zone of Proximal Development (ZPD) and Vygotsky's (1987) Socio Cultural Theory (SCT). The assumption is that the learners participate in the social events created in the classroom in order to interact with each other in a supportive zone and create social networks for themselves. The unplugged classroom is light in material which means learners are not exposed to textbooks but they are supposed to speak more in the classroom rather than following the textbook rules. Therefore, the contents are not delivered in a linear order; rather they will be delivered based on the daily needs of the learners. Dogme ELT is based on emergent language. Emergent language was formerly proposed by Brown (2001). In the unplugged era learning has been emerged according to the learners' exigent needs and the presentation of the material postponed to the end of the teaching process. This implies that teaching phases are inextricably linked to the syllabus to be presented (Thornbury, 2002, 2005, 2017).

However, this concept has not been tapped in depth for the Iranian EFL learners' community. With respect to other learning communities, research indicated that most of these communities for improving oral proficiency are restricted to a number of skills. For example, most studies on flipped classrooms for teaching English have only been carried out for a limited number of subjects (Joanne \& Lateef, 2014). Therefore, the present study explores for the first time the effects of two non-conventional classrooms including unplugged classroom and flipped classroom for teaching English oral proficiency to EFL learners in the Iranian context. In this research, the following questions regarding the possible impact of these learning communities on Iranian EFL learners' oral proficiency are sought to be answered:

RQ1: What are the differences between the conventional and non-conventional instructions in Iranian learners' oral proficiency? 
RQ2: What are the Iranian learners' perceptions towards learning English through flipped instruction?

RQ3: What are the Iranian learners' perceptions towards learning English through unplugged instruction?

RQ4: What are the Iranian participants' total viewpoints towards learning English through flipped instruction?

RQ5: What are the Iranian participants' total viewpoints towards learning English through unplugged instruction?

\section{LITERATURE REVIEW}

\section{Flipped Classroom Model (FCM) in the EFL context}

The idea of "Flipped classroom" was taken from Bergmann and Sams (2007) for the purpose of recording the lectures and lessons for the learners who missed a session and then transferring such material into PowerPoint and other accessible sources for the rest of learners to review. Then as it is presented by Chen, Wang, Kinshuk and Chen (2014), it was by Khan (2011) that the concept "flipped classroom" popped up through the TED talk as a model of language learning with a wide gamut of videos on different subjects of studies. There are some online frameworks and models available for flipping the classroom. Amongst, the FCM proposed by Bergmann, Overmyer, and Wilie (2011) is very popular. This model is a trichotomy consisting of online videos, physical classes, and interactive platforms. Bishop and Verleger (2013) delivered a dichotomy for the flipped learning consisting of computer mediated materials and interaction oriented activities. Besides these FCMs, Chen, et al. (2014) presented a seven-pillar FCM for flipping the classrooms in which FLIPPED is short for "Flexible environment", "Learning culture", "Intentional content", "Professional education", "Progressive networking learning activities", "Engaging and effective learning activities", "Diversified and seamless learning platforms".

There is a great consensus amongst the flipped users that it may result in boosting learning and expanding interactive networks via communicating the selves and exchanging ideas (Baepler, Walker \& Driessen, 2014; Mason, Shuman, \& Cook, 2013; Wu, 2016; Wu et al., 2017; Zhai et al., 2017). Relevant to the followers of the concept, Zhonggen and Wang (2016) by analyzing the effectiveness of flipped classroom found that flipped classroom resulted in more satisfaction and self-regulation from the part of the learners by giving more opportunities to practice their writings from wherever they could. Boucher et al. (2013) are of the idea that meaningful activities in the flipped era will lead to boosting learning products and learners' satisfaction. It is also taken from the findings of Wu, et al. (2017), that flipped classroom results in the improvement of EFL learners' oral proficiency and it also motivates the learners to participate more actively in collaborative and self-directed activities in online courses. Most of the research on flipped classroom intermittently proved learners' avoidance from completing the flipped practices (Afrilyasanti, Cahyono, \& Astuti, 2016; Huelskamp, 2015; Roshan, 2013; Zhang, 2017). Besides, much of the current literature on flipped classroom takes into 
account the styles and strategies that have been mostly used by the learners while flipping their own learning in online courses. Just as an example, Zhang (2017) worked on the effectiveness of flipped courses concerning strategies that can elevate the quality of college English teaching.

\section{Unplugged Classroom Model (UCM) and Dogme in English Language Teaching (ELT)}

The terms "Unplugged teaching" and "Dogme" in language teaching were coined by Thornbury (2005) for the very first time. However, the concept was inspired by Dogme 95 filmmaking movement in Denmark aiming at cleaning the cinemas from the flamboyant Hollywood touches and according to Thornbury the concept of dogme in teaching is a movement in ELT that cleanses the teaching process from the amount of useless and time-consuming materials. Whilst, the first movement focused on the real story in the film instead of the showy details, the second movement vowed for putting more emphasis on the learners' real communicative needs rather than the colorful textbooks. The principles proposed by Thornbury (2005), later were developed by the work of Meddings (2015) in twenty comprehensive points. As it was later clarified by the fathers of the unplugged revolution, the main components of dogme ELT consist of three pillars including:

1. It is Conversation-driven so that the classroom is based on conversations and learners play an active role in deciding on the content of conversation. Meddings (2015) states that attention has been placed over the interaction zone in the classroom which is rooted in Vygotsky's (1978) Zone of Proximal Development (ZPD) and also Vygotsky's (1987) Socio Cultural Theory (SCT).

2. It is light in material which means learners are not exposed to textbooks and learners are supposed to speak more in the classroom rather than following the commands of the textbook.

3. It is based on emergent language. Emergent language was first proposed by Brown (2001). As the phrase "emergent language" stands for, learning has been emerged according to the learners' emergent needs.

As Thornbury (2001) states, the most challenging aspect of unplugged classroom for the EFL learners and the teachers is learners and teachers' incredibility to the effectiveness of conversation-driven classroom over textbook-driven syllabus. To put an end to this dilemma, Thornbury (2001) recommends the teachers that instead of being too much dependant on the course book rely on the voices, the individuals, and learners' needs by practicing the conversations to find about the soothing effect of this dialogic model as a remedy for the traditional methods' wounds.

Ushioda (2011) explains that dogme ELT puts emphasis on conversations among learners and teacher in real-like situation controlled by learners. To put it simply, dogme ELT is a reflection of learners' voices to be heard and their exigent needs to be satisfied not by the textbook but by teacher's support (Banegas, 2012). Although unplugged teaching seems very flexible in terms of implementation there still remains some 
problems for the teachers on the application of such procedure in their classroom (Banegas, 2012; Bryndal, 2014; Sketchley, 2011, 2012). The problem as Akca (2012) limns is that different learners with miscellaneous learning (dis)abilities demand a variety of pedagogical procedures which makes it difficult for the teachers to teach unpluggedly. However, Akca (2012) recommends more research about the new coming concept for having a better panoramic worldview about Thornbury's dogme. Like Sketchley (2011) and Chong (2016) that worked on the unplugged teaching and were interested in the mechanism of dogme in ELT, Xerri (2012) applied dogme in an actionresearch-attempt. He expounded on some merits and demerits of implementing unplugged teaching with reference to the writing and speaking activities. Learners in Xerri's study benefited from the peer-peer and teacher-peer conversations on the selected subjects and enjoyed the chance of being counted in self-expression practices which was a reflection of Meddings and Thornbury's (2009) view point towards the importance of individuals.

\section{METHOD}

\section{Design of the Study}

The study was quasi-experimental because learners from intact classes were asked to participate in the study. The assignment of the classes to the experimental and the control groups was random. Furthermore, a factorial design was used because two independent variables, namely unplugged and flipped classrooms were at work. Concerning the design of the study, a pretest-posttest design was utilized and both quantitative and qualitative research methods (mixed method) were applied (Figure 1).

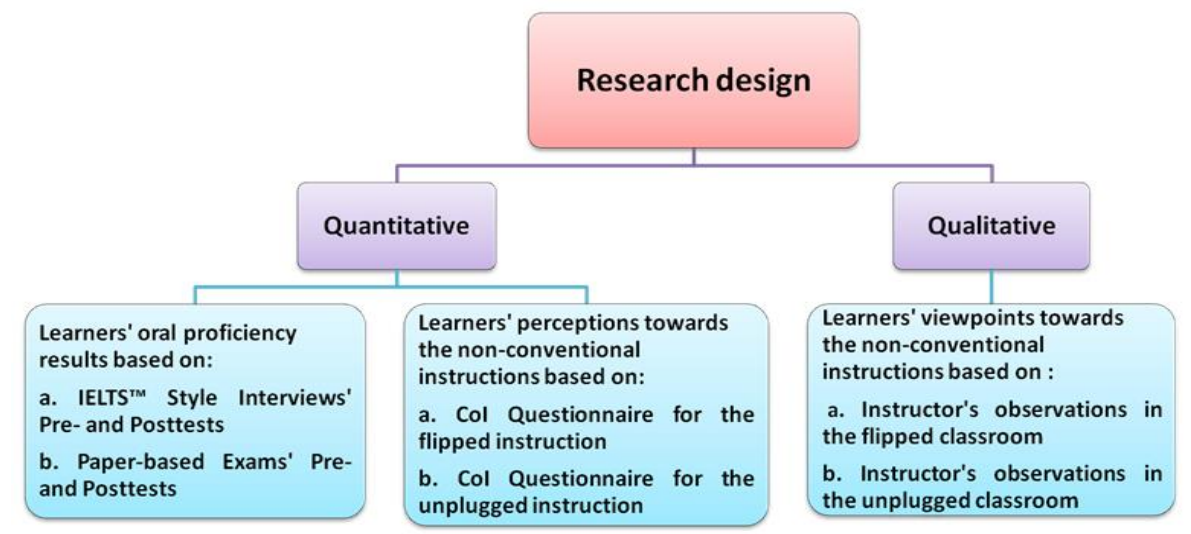

Figure 1

The Design of the Current Study

\section{Participants}

The population was 246 Iranian EFL learners (73 males and 173 females) with ages ranging from 15 to 35, who were taking English classes in Raaz Language Institute in Isfahan, Iran. All of the participants had passed Richards and Bohlke's (2012a), FOUR 
CORNERS Level 1 as the primary course book, but they also had different English backgrounds from their English course books at school or from other English language institutes. Subsequently, to assure the participants' homogeneity, they were tested through the SPEAK NOW 1-4 Interview Placement Exam prepared by Richards and Bohlke (2012b). Afterwards, 90 upper-intermediate participants were randomly selected from a cohort of 246 learners who were then randomly assigned to two experimental groups $(\mathrm{N}=60)$ and one control group $(\mathrm{N}=30)$.

\section{Pretest and Posttest}

The pretest and posttest for the conventional and non-conventional instructions were identical including the IELTSTM Style Interview test with a list of interview questions classified from easy (SPEAK NOW Level 1) to difficult (SPEAK NOW Level 3) in addition to a Paper-based exam for measuring learners' oral comprehension. In order to guarantee the inter-rater reliability of the IELTSTM Style Interview, the evaluation criteria were taken from Richards and Bohlke's (2012b) IELTS ${ }^{\text {TM }}$ Style Interview scoring rubrics based on (1) Pronunciation and Intonation, (2) Lexical Control, (3) Grammatical Accuracy, and (4) Spoken Fluency, with the rankings from 0 with little or no mastery to 3 with outstanding mastery and the inter-rater reliability of the IELTS ${ }^{\mathrm{TM}}$ Style Interview evaluated based on Krippendorff's alpha at .95 , revealing a satisfactory reliability for the present study (Hayes \& Krippendorff, 2007). The Paper-based exam was evaluated based on three criteria including listening ability, vocabulary, and language function. The overall reliability of the Paper-based exam based on Cronbach's alpha value was 0.86 , suggesting a high level of reliability. Furthermore, the scoring in the IELTS ${ }^{\text {тM }}$ Style Interview was independent and specific for each question to the point that learners' response to each question was examined based on the four scoring rubrics. While, the scoring in the Paper-based exam was integrative and learners' oral comprehension was considered as a whole. To measure learners' satisfaction and perception towards the non-conventional instructions, besides the IELTS ${ }^{\text {TM }}$ Style Interview and Paper-based exam in the posttest the CoI questionnaire was adopted from $\mathrm{Wu}$, et al. (2017). The reliability of the CoI questionnaire was estimated based on Cronbach's alpha at .93 representing a great internal consistency among the three presences in the CoI questionnaire including teaching, social and cognitive presences with the Cronbach's alpha estimates of $.93, .91$, and .96 respectively.

\section{Procedures}

To accomplish the purpose of the study, all the participants received the same amount of input including SPEAK NOW Level 2 with identical topics consisting of "Starting a conversation", "Asking about personalities", "Style and fashion", and "Sharing experiences with food". The reason for selecting these topics was simply the priority of learners' communicative needs and the application of these topics in everyday life. In the control group, the teacher addressed the textbook's' guidelines for examining the sole effect of teaching based on the textbook on learners' oral performance.

\section{Flipped Instruction Procedures}

The participants in the FCM were exposed to the WhatsApp application for their online activities before the class. WhatsApp was applied for various reasons. Firstly, it is 
secure for sharing and accessing information in different formats. Secondly, it is easy to install and use. Before the course, learners' ability to use the app had been checked. For the activities before the classroom, the participants in the FCM were asked to listen to a BBC 6-minute English podcast and after summarizing the listening part, they had to record their summary and upload it on their online platform. The podcasts were in line with the book topics including: "How to start and how to close a conversation", "Glass half full", "The meaning of clothes", and "Food and mood". The teacher together with the students had to give feedback on the recorded performances. In class, the teacher asked some questions concerning the podcast and encouraged learners to discuss the topic in a collaborative way. Then after the class, the teacher uploaded the concluding remarks and extra points about the discussed topic on the learners' online platform (As shown in Figure 2).
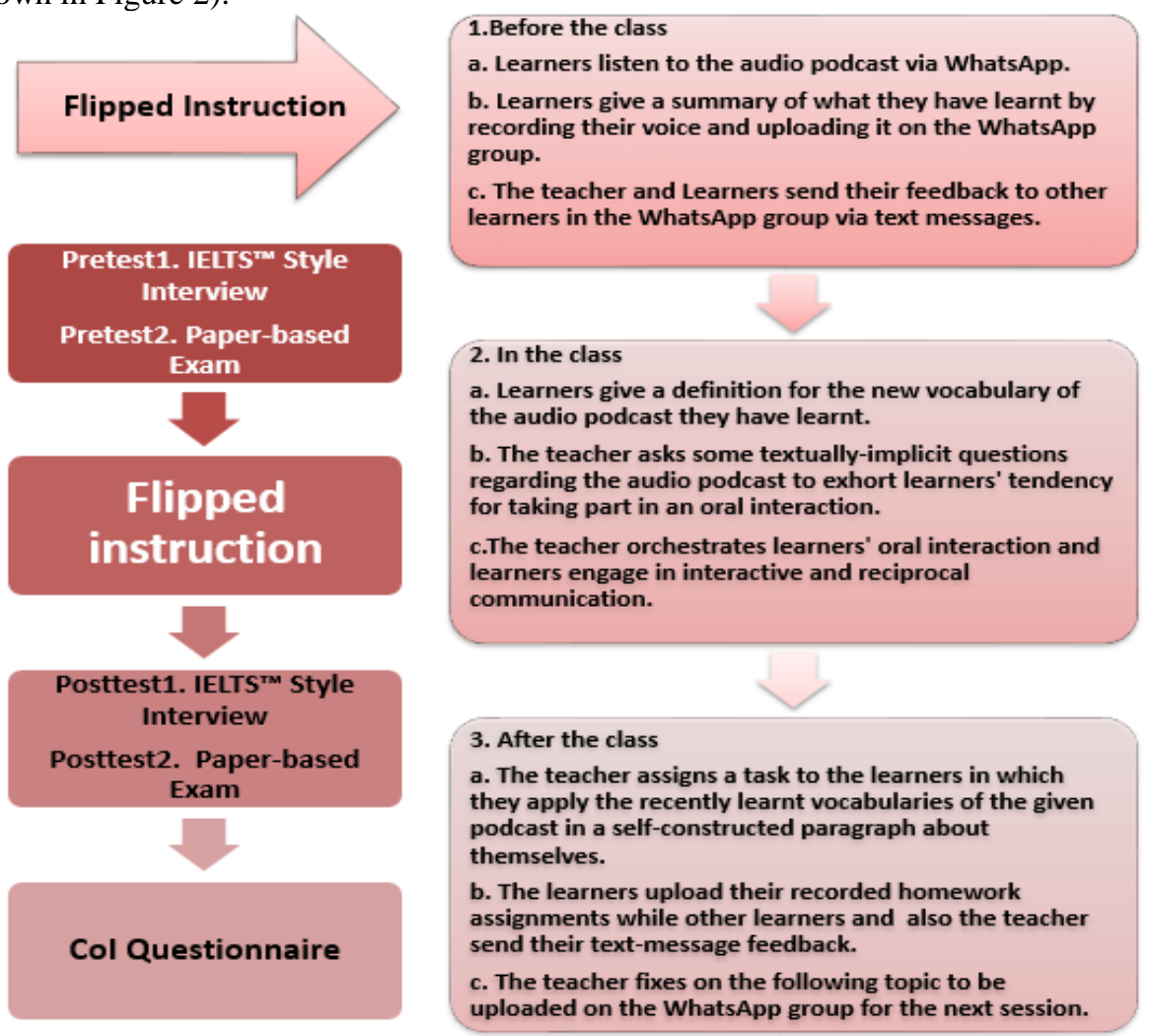

Figure 2

The FCM's Procedures for the Current

\section{Unplugged Instruction Procedures}

For running the unplugged instruction, the general procedures were based on Meddings and Thornbury's (2009) "Teaching Unplugged", and Meddings' (2015) YouTube video 
on the 20 steps for teaching UCM. Although the class activities were based on lightmaterial and conversation-driven tasks, learners had the possibility to refer to their book for more practice. For evaluating learners' perception towards the UCM a modified version of the CoI questionnaire was taken to satisfy the objectives of unplugged instruction. In the UCM, the teacher had to extend their unplugged syllabus based on Dogme ELT teaching scenario. In the 'Set it up' stage, teacher asked students to talk about the related vocabulary or expressions they knew about the topic. In the following phase, or the 'Let it run' stage, the teacher put students in pair groups, while students were engaged in dyadic interactions. The teacher also wrote the conversational patterns on the board to help learners to scaffold their learning by applying the patterns on the board for their conversations. Moreover, the teacher wrote new words and expressions as emerged during the groups' conversations. In the 'Round it off' stage the teachers had to keep the social zone in the class to be continued by asking individuals to make sentences with the new words and expressions and practice the conversation with other classmates (As shown in Figure 3).

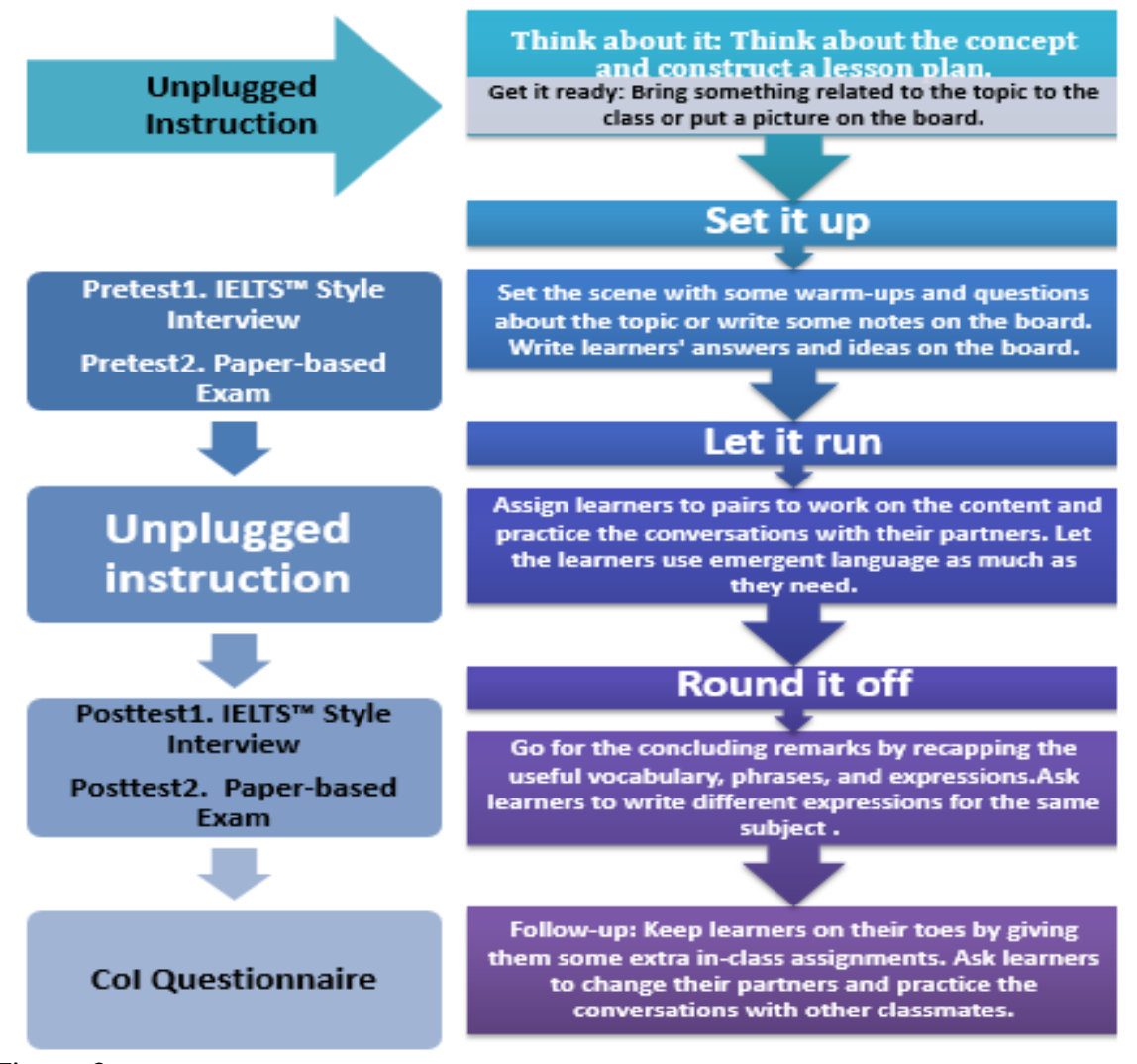

Figure 3

The UCM's Procedures for the Current Study 


\section{Data Collection and Analysis}

The study was a 4-week treatment and the data from the three classrooms were collected from learners' pretests and posttests, besides surveys' results and the instructors' observations (Figure 4) in the experimental groups. To analyze the data at the quantitative level, learners' pretests and posttests were compared according to two scales. First, to answer research question one the speaking abilities of the unplugged and flipped learners were compared to the performances of their counterparts in the control group. Second, the performances of the unplugged and flipped learners were compared with each other and learners' perception towards unplugged and flipped classrooms were analyzed based on CoI questionnaire regarding research questions two and three. Moreover, the study took one-way ANOVA. At the qualitative level, however, the unplugged and flipped learners' overall experiences and viewpoints towards these instructions based on instructor's observations were analyzed to answer research questions four and five. The scale for instructor's observations was on the bases of four factors including 1) Total involvement in the non-conventional program, 2) Practicality of the instruction, 3) Productive interaction and promising feedback, and 4) Independent learning and perceived perception adopted from $\mathrm{Wu}$, et al. (2017) with some modifications to fit the purposes of the present study.

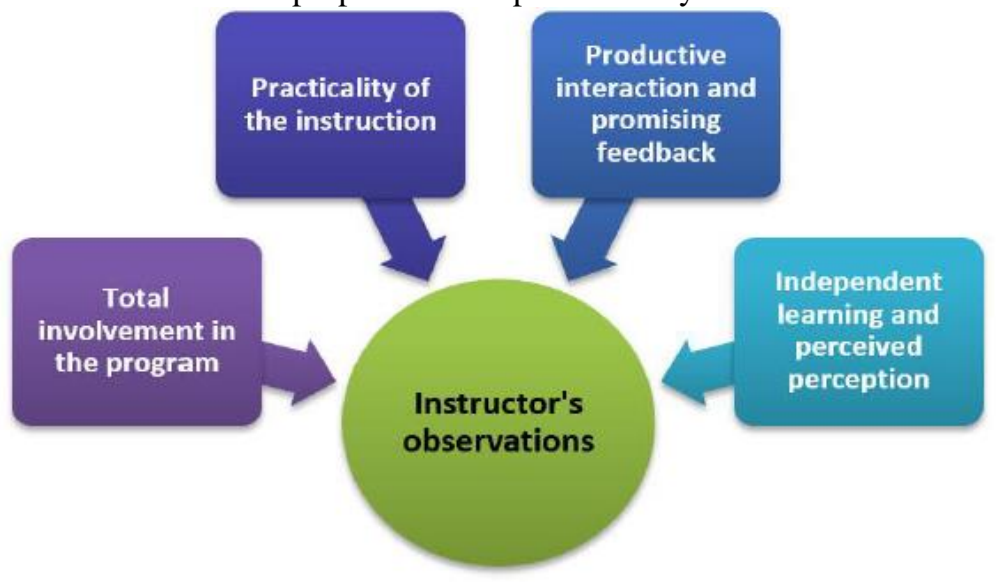

Figure 4

Instructor's Observations in the Current Study

\section{FINDINGS}

RQ1: What was the difference between the conventional and non-conventional instructions in Iranian learners' oral proficiency?

The results of the learners' IELTSTM Style Interviews' pretests and posttests indicated that interviewees' posttest scores were remarkably higher than their pre-test scores in all the three groups. As shown in Table 1, the instructions in the three groups were efficacious but not exactly with the same rate of impact. Based on the results of interviewees' minimum scores in the pre-test, as it is illustrated in Table 1 the minimum 
scores were identical in the three groups $(\mathrm{Min}=1.80)$, while in the posttests the controlgroup interviewees were the least eminent producers of orally proficient utterances (Min $=2.20$ ) since the classroom was only based on the book's commands. On the other hand, the flipped interviewees $(\mathrm{Min}=2.40)$ besides the unplugged interviewees $(\operatorname{Min}=2.30)$ were much more successful in producing orally acceptable utterances. Comparing the maximum scores of the three groups, the findings revealed that although the three groups had the same maximum score $(\operatorname{Max}=2.10)$ in their pre-test interviews, the maximum scores of the two non-conventional classroom including the FCM (Max = $2.90)$ and the UCM (Max = 2.60) were dramatically higher than the maximum score of the conventional classroom $(\mathrm{Max}=2.50)$ in the posttest.

Table 1

Descriptive Statistics of Learners' IELTS ${ }^{\text {TM }}$ Style Interviews' Pretests and Posttests

\begin{tabular}{|c|c|c|c|c|c|c|c|c|}
\hline group & & $\mathrm{N}$ & Minimum & Maximum & Mean & Std. Deviation & Statistics $(\mathrm{Z})$ & Sig. \\
\hline \multirow[t]{2}{*}{ control } & Pretest & 30 & 1.80 & 2.10 & 1.92 & .114 & \multirow{2}{*}{-4.811} & \multirow{2}{*}{$<.001$} \\
\hline & Posttest & 30 & 2.20 & 2.50 & 2.31 & .104 & & \\
\hline \multirow[t]{2}{*}{ FCM } & Pretest & 30 & 1.80 & 2.10 & 1.94 & .107 & \multirow{2}{*}{-4.800} & \multirow{2}{*}{$<.001$} \\
\hline & Posttest & 30 & 2.40 & 2.90 & 2.75 & .138 & & \\
\hline \multirow[t]{2}{*}{ UCM } & Pretest & 30 & 1.80 & 2.10 & 1.94 & .114 & \multirow{2}{*}{-4.799} & \multirow{2}{*}{$<.001$} \\
\hline & Posttest & 30 & 2.30 & 2.60 & 2.49 & .104 & & \\
\hline
\end{tabular}

All in all, based on the findings of Table 1 and the results of Wilcoxon Signed Ranks Test, the IELTS ${ }^{\text {тM }}$ Style Interview scores at the three groups were normally higher in the posttests than in the pre-tests $(p<0.05)$. This implied that instructions in the three groups were effective and contained proficiency-oriented materials. On the bases of interviewees' performances, it could be inferred that the FCM techniques were outstandingly more effective and the procedures were implemented better than the two other classrooms' techniques and procedures. Moreover, the posttest means scores of the three classrooms verified the usefulness of flipped materials $(M=2.75)$ over the unplugged $(M=2.49)$ and conventional materials $(M=2.31)$.

The analysis of the Paper-based pretests and posttests with reference to Table 2 demonstrated that the paper-based pretests' minimum score in the UCM and the control group classroom were exactly the same $(\operatorname{Min}=1.90)$, however in the posttest the minimum score of the UCM (Min = 2.40) was to some extent higher than the minimum score of the control-group classroom (Min $=2.30)$. In contrast, the minimum score of the FCM in both pretest $(\mathrm{Min}=2.00)$ and posttest $(\mathrm{Min}=2.60)$ was noticeably higher than the two other groups. The Paper-based results revealed identical maximum scores for the three groups in the pretest $(\operatorname{Max}=2.40)$ but diverged maximum scores in the posttests. As such, the findings of the posttests indicated that there was a very slight difference between the maximum scores of the control group classroom ( $\mathrm{Max}=2.50$ ) and the UCM $(\operatorname{Max}=2.60)$. The comparison of Paper-based pretests and posttests among the three groups showed that the FCM (Max = 2.90) outperformed the other classrooms. 
Table 2

Descriptive Statistics of Paper-based Pretests and Posttests

\begin{tabular}{|c|c|c|c|c|c|c|c|c|}
\hline group & & $\mathrm{N}$ & Minimum & Maximum & Mean & $\begin{array}{l}\text { Std. } \\
\text { Deviation }\end{array}$ & $\begin{array}{l}\text { Statistics } \\
\text { (Z) }\end{array}$ & Sig. \\
\hline \multirow[t]{2}{*}{ control } & Pretest & 30 & 1.90 & 2.40 & 2.13 & .16 & \multirow{2}{*}{-4.675} & \multirow{2}{*}{$<.001$} \\
\hline & Posttest & 30 & 2.30 & 2.60 & 2.46 & .10 & & \\
\hline \multirow[t]{2}{*}{ FCM } & Pretest & 30 & 2.00 & 2.40 & 2.19 & .13 & \multirow{2}{*}{-4.799} & \multirow{2}{*}{$<.001$} \\
\hline & Posttest & 30 & 2.60 & 3.00 & 2.87 & .12 & & \\
\hline \multirow[t]{2}{*}{ UCM } & Pretest & 30 & 1.90 & 2.40 & 2.12 & .16 & \multirow{2}{*}{-4.801} & \multirow{2}{*}{$<.001$} \\
\hline & Posttest & 30 & 2.40 & 2.70 & 2.60 & .10 & & \\
\hline
\end{tabular}

In addition to the aforementioned findings based on Table 2, the assessment of the data according to Wilcoxon Signed Ranks Test showed the improvement of learners' Paperbased scores in the posttest in all the three classrooms as a result of three types of instructions. Comparing the score differences in the pretests and posttests in all the three upper-intermediate groups, the results based on Table 3 showed the highest score difference from pretests to the posttest in the FCM with much higher minimum (Min = $0.40)$ and maximum $(\operatorname{Max}=1.10)$ scores than that of the UCM with lower minimum $(\operatorname{Min}=0.20)$ and maximum scores $(\operatorname{Max}=0.80)$ and the control-group classroom with very low minimum $($ Min $=0.10)$ and maximum $($ Max $=0.70)$ scores.

Table 3

Score Differences between IELTS ${ }^{\text {TM }}$ Style Interviews' Pretests and Posttests

\begin{tabular}{llllllll}
\hline group & $\mathrm{N}$ & Minimum & Maximum & Mean & Std. Deviation & Statistics $\left(\chi^{2}\right)$ & Sig. \\
\hline control & 30 & .10 & .70 & .39 & .16 & & \\
FCM & 30 & .40 & 1.10 & .80 & .21 & 18.446 & $<.001$ \\
UCM & 30 & .20 & .80 & .54 & .17 & & \\
\hline
\end{tabular}

The posttests result of upper-intermediate learners' IELTS ${ }^{\text {TM }}$ Style interviews (see Table 3 ) demonstrated a considerably meaningful improvement in the performances of all the three classrooms including the conventional classroom $(M=0.39)$, the UCM $(M=$ $0.54)$ and the FCM $(M=0.80)$. In other words, on the basis of the Kruskal Wallis Test there was a dramatically noticeable divergence among the three groups' mean differences from pre-test to the posttest.

Table 4

Pair-Wise Comparison of Mean Differences between IELTS ${ }^{\text {TM }}$ Style Interviews' Pretests and Posttests

\begin{tabular}{llll}
\hline group & Mean Difference & Statistics & Sig. \\
\hline Control- FCM & -.41 & -17.917 & .022 \\
Control - UCM & -.15 & -43.283 & $<.001$ \\
FCM -UCM & .26 & 25.367 & $<.001$ \\
\hline
\end{tabular}

Therefore, according to the pair-wise comparison of the upper-intermediate learners' mean differences in IELTS ${ }^{\text {TM }}$ Style interviews (as shown in Table 4) the FCM's posttest interview scores increased much more than that of the UCM and the control-group classroom. The results of the score differences demonstrated that the unplugged scores were to some extent higher than the control-group scores regarding the differences between the pre-test and the posttest $(p<0.05)$. Based on the comparison of the mean 
differences among the three groups, the results showed that the unplugged instruction was also more effective than the conventional instruction.

The Paper-based pretests and posttests' score differences on the other hand according to the findings of Table 5 revealed that learners' posttest performances in all the three groups dramatically boosted compared with their pre-test performances. The results of the score differences between learners' pretests and posttests showed that the flip learners enjoyed the practical communication in an appropriate setting more than the two other groups equipped with other instructions. As a result, the FCM's mean score difference from pretest to the posttest $(M=0.68)$ was much higher than that of the UCM $(M=0.48)$ and the control-group $(M=0.33)$. Evidently, the FCM's instruction was more promising for the upper-intermediate learners than the unplugged and conventional methods.

Table 5

Score Differences between Paper-based Exams' Pretests and Posttests

\begin{tabular}{llllllll}
\hline group & $\mathrm{N}$ & Minimum & Maximum & Mean & Std. Deviation & Statistics $\left(\chi^{2}\right)$ & Sig. \\
\hline control & 30 & -.10 & .70 & .33 & .19 & & \\
FCM & 30 & .30 & 1.00 & .68 & .19 & 12.814 & $<.001$ \\
UCM & 30 & .10 & .80 & .48 & .20 & & \\
\hline
\end{tabular}

The findings based on the Kruskal Wallis Test stressed the meaningful difference between learners' Paper-based pretests and posttests in the three groups $(p<0.05)$. The pair-wise comparison of the mean differences in the Paper-based test, based on the Mann-Whitney test (see Table 6) demonstrated that there was a statistically significant mean difference with reference to the comparison of the FCM and the control-group classroom $(M D=0.35)$, whereas the mean difference between the FCM and the UCM $(M D=0.20)$ was not very noticeable. Besides, the mean difference between the UCM and the control group classroom $(M D=0.15)$ was quite insignificant.

Table 6

Pair-Wise Comparison of Mean Differences between Paper-based Exams' Pretests and Posttests

\begin{tabular}{llll}
\hline group & Mean Difference & Statistics & Sig. \\
\hline Control- FCM & -.35 & -15.833 & .201 \\
Control - UCM & -.15 & -37.717 & $<.001$ \\
FCM -UCM & .20 & 21.883 & .005 \\
\hline
\end{tabular}

The total comparison of the IELTS ${ }^{\mathrm{TM}}$ Style interview scores in both pretests and posttests in every group illustrated that although the minimum score $($ Min $=1.80)$ and the maximum score $(\mathrm{Max}=2.10)$ in all the three groups were identical in the pretest, the maximum score and the minimum score of all the groups dramatically increased in the posttest. Moreover, the difference between the scores of the unplugged interviewees and control group interviewees was mutually inconsiderate. The findings alluded to the fact that the flipped interviewees' posttest scores (see Table 7) were considerably higher in both minimum $(\operatorname{Min}=2.40)$ and maximum $(\operatorname{Max}=2.90)$ points. 
Table 7

IELTS ${ }^{\text {TM }}$ Style Interviews' Group Differences

\begin{tabular}{lllllllll}
\hline & group & $\mathrm{N}$ & Minimum & Maximum & Mean & Std. Deviation & Statistics $\left(\chi^{2}\right)$ & Sig. \\
\hline \multirow{2}{*}{ Pre } & control & 30 & 1.80 & 2.10 & 1.92 & .114 & & \\
test & FCM & 30 & 1.80 & 2.10 & 1.94 & .107 & .000 & .988 \\
& UCM & 30 & 1.80 & 2.10 & 1.94 & .114 & & \\
\hline \multirow{2}{*}{ Post } & control & 30 & 2.20 & 2.50 & 2.31 & .104 & & \\
test & FCM & 30 & 2.40 & 2.90 & 2.75 & .138 & 34.081 & $<.001$ \\
& UCM & 30 & 2.30 & 2.60 & 2.49 & .104 & & \\
\hline
\end{tabular}

Based on the Kruskal Wallis Test results, there was no meaningful difference among the FCM, UCM and control-group classroom's performances in the IELTS ${ }^{\text {TM Style }}$ interviews' pretests $(p>0.05)$. In contrast, in the posttests the difference was very significant to the extent that the FCM outperformed the control group classroom and the UCM $(p<0.05)$. The pair-wise comparison of the IELTS ${ }^{\text {TM }}$ Style interviews' pretests and posttests group differences and the Man-Whitney test findings (as shown in Table 8) indicated that the flipped learners were highly successful after the instruction in comparison to the unplugged and the control group learners.

Table 8

Pair-Wise Comparison of IELTS ${ }^{\mathrm{TM}}$ Style Interviews' Group Differences

\begin{tabular}{llll}
\hline group & Mean Difference & Statistics & Sig. \\
\hline Control- FCM & -.43 & -23.733 & .001 \\
Control - UCM & -.17 & -53.367 & $<.001$ \\
FCM -UCM & .26 & 29.633 & $<.001$ \\
\hline
\end{tabular}

The Kruskal Wallis Test results of the Paper-based pretests and posttests (see Table 9) indicated that like the IELTS ${ }^{\mathrm{TM}}$ Style Interview pretests there was no meaningful difference among the three groups' performances in the Paper-based pretest $(p>0.05)$. However, the posttest's results showed a remarkably meaningful difference among the performances of the three groups. The observed increase in learners' posttest could be attributed to the significance of instruction in the three groups $(p<0.05)$. Taken together, these results suggested that the FCM instruction $(M=2.87)$ was more successful, while, these results did not rule out the influence of the two other instructions. The unplugged instruction $(M=2.60)$, on the other hand, was more effective than the control group instruction $(M=2.46)$.

Table 9

Paper-based Exams' Group Differences

\begin{tabular}{lllllllll}
\hline & group & N & Minimum & Maximum & Mean & $\begin{array}{l}\text { Std. } \\
\text { Deviation }\end{array}$ & $\begin{array}{l}\text { Statistics } \\
\left(\chi^{2}\right)\end{array}$ & Sig. \\
\hline \multirow{3}{*}{ Pre test } & control & 30 & 1.90 & 2.40 & 2.13 & .16 & & \\
& FCM & 30 & 2.00 & 2.40 & 2.19 & .13 & 3.250 & .071 \\
& UCM & 30 & 1.90 & 2.40 & 2.12 & .16 & & \\
\hline \multirow{3}{*}{ Post test } & control & 30 & 2.30 & 2.60 & 2.46 & .10 & & $<.001$ \\
& FCM & 30 & 2.60 & 3.00 & 2.87 & .12 & 37.047 & \\
& UCM & 30 & 2.40 & 2.70 & 2.60 & .10 & & \\
\hline
\end{tabular}

The results of the Mann-Whitney test (see Table 10) considering the pair-wise comparison of mean differences demonstrated that in the Paper-based test, the difference 
between the performances of FCM and control group classroom $(M D=0.41)$ was much higher than the difference between the performances of FCM and UCM $(M D=0.27)$ on the one hand, and the difference between the performances of the control-group classroom and the UCM $(M D=0.14)$ on the other hand.

Table 10

Pair-Wise Comparison of Paper-based Exams' Group Differences

\begin{tabular}{llll}
\hline group & Mean Difference & Statistics & Sig. \\
\hline Control- FCM & -.41 & -21.500 & .004 \\
Control - UCM & -.14 & -53.300 & $<.001$ \\
FCM -UCM & .27 & 31.800 & $<.001$ \\
\hline
\end{tabular}

RQ2: What were the Iranian learners' perceptions towards learning English through flipped instruction?

In order to rate the CoI questionnaire respondents were asked to rate their level of agreement to the sentences in each presence in a five-point Likert-type scale from 1(strongly disagree) to 5 (strongly agree). It can be seen from Table 11 that the mean score was considerably high in the teaching presence section $(M=63.10)$. The results indicated that learners were satisfied with the instruction and the way the FCM was presented. The mean score of the flipped learners in the social presence $(M=42.70)$ was lower than their mean score in the teaching presence $(M=63.10)$. Thereafter, the mean score of learners in the cognitive presence $(M=55.87)$ moved further to a considerably increasing point in comparison to their mean scores in the social presence $(M=42.70)$.

Table 11

Descriptive Statistics of Three Presences for FCM

\begin{tabular}{llllll}
\hline \multirow{2}{*}{ group } & Scale & FCM & & Statistics (U) & Sig. \\
\cline { 3 - 6 } & Mean & $\begin{array}{l}\text { Std. } \\
\text { Deviation }\end{array}$ & & \\
\hline \multirow{2}{*}{ FCM } & Teaching Presence & 63.10 & 2.12 & 1.000 & $<.001$ \\
& Social Presence & 42.70 & 2.04 & .000 & $<.001$ \\
& Cognitive Presence & 55.87 & 2.19 & .000 & $<.001$ \\
\hline
\end{tabular}

RQ3: What were the Iranian learners' perceptions towards learning English through unplugged instruction?

In the unplugged instruction as Table 12 set out, the mean score of the teaching presence $(M=50)$ was higher than the mean score of the social presence $(M=37.47)$. It can be inferred from Table 12 that although the focus of the instructor was much on the conversations emerged in the classroom with less dependence on the printed material, learners in the UCM were satisfied with this non-conventional instruction. Overall, these results indicated that the mean score of unplugged learners' social presence $(M=37.47)$ was to some extent lower than the teaching presence $(M=50)$. Therefore, as shown in Table 12 based on the Mann-Whitney test results the mean score of the participants' cognitive presence in the UCM $(M=49.30)$ was statistically higher than their mean scores in the social presence $(M=37.47)$. 
Table 12

Descriptive Statistics of Three Presences for UCM

\begin{tabular}{|c|c|c|c|c|c|}
\hline \multirow[b]{2}{*}{ group } & \multirow[b]{2}{*}{ Scale } & \multicolumn{2}{|l|}{ UCM } & \multirow[b]{2}{*}{ Statistics (U) } & \multirow[b]{2}{*}{ Sig. } \\
\hline & & Mean & $\begin{array}{l}\text { Std. } \\
\text { Deviation }\end{array}$ & & \\
\hline \multirow{3}{*}{ UCM } & Teaching Presence & 50.00 & 3.92 & 3.500 & $<.001$ \\
\hline & Social Presence & 37.47 & 3.51 & 65.000 & $<.001$ \\
\hline & Cognitive Presence & 49.30 & 2.52 & 11.000 & $<.001$ \\
\hline
\end{tabular}

The comparison of the flipped instruction vs. unplugged instruction revealed that flipped learners were more satisfied with the instruction presented via online platform $(M=$ 63.10). The unplugged learners showed less satisfaction in teaching presence $(M=50)$ as they could not exactly declare that the course goals were tapped in the unplugged instruction or not. In the social presence, on the other hand, the perception of flipped learners was to some extent higher $(M=42.70)$ than their unplugged counterparts $(M=$ 37.47). The cognitive presence for both FCM $(M=55.87)$ and UCM $(M=49.30)$ was effective.

\section{RQ4: What were the Iranian participants' total viewpoints towards learning English through flipped instruction?}

With reference to the implemented FCM in the present study and based on the reported findings in other flipped communities (Zhai et al., 2017; Wu et al., 2017) four indispensably broad themes consisting of 1) Total involvement in the flipped program, 2) Practicality of flipped instruction, 3) Productive interaction and promising feedback, and 4) Independent learning and perceived perception, have been recognized. The themes came up to discussions of the participants' reactions towards the flipped instruction, podcasts together with their subsequent tasks, and finally the mutual communication sustained from the course's feedback.

\section{Total Involvement in the Flipped Program}

In all cases, the participants reported that in contrast to the fast listening comprehension tasks in the previously experienced conventional classrooms, they had enough time to spend on the listening parts and they had the opportunity to discuss the meaning with other learners in the flipped environment. On the contrary, a minority mentioned that the first flipped sessions were to some extent time consuming for them. One learner argued "I had to listen three or four times to the podcasts to get the gist but after three sessions I felt that my listening ability had promoted and I was able to understand the podcasts only after listening once or twice."

\section{Practicality of Flipped Instruction}

Although, a minority of participants mentioned that the instructor's supportive actions in guiding the class towards understanding course topics were praiseworthy, all agreed that making the participants involved in tasks and reinforcing actions of the instructor for developing a sense of community among learners led to successful instruction. Another sustained theme emerged from instructor's timely feedback. 


\section{Productive Interaction and Promising Feedback}

Interestingly, most of the participants alluded to the notion that with successive increase in the intensity of the podcasts, their listening ability moved further to asset their speaking in particular and their oral proficiency in general. As one participant said, "Performing the activities in a teamwork frame with other participants gave me a sense of belonging in the online group." In one case, one participant stated, "Communicating with other classmates and the teacher in English language developed my vocabulary and enabled me to correct my own mistakes without the teacher's assistance."

\section{Independent Learning and Perceived Perception}

The teacher's and other learners' feedback besides online discussions led to strong scaffolds for coming over the weaknesses. In the virtual zone of proximal growth learners became aware of their own mistakes. Talking about this issue, one participant said, "Something that I used to hesitate was presenting in front of others and WhatsApp was a useful asset as I learned how to express my ideas in an online community and how to organize new knowledge and expand my understanding via summarizing and discussing meaning with other learners."

RQ5: What were the Iranian participants' total viewpoints towards learning English through unplugged instruction?

Like the flipped instruction, in the unplugged instruction a number of issues were identified including 1) total involvement in the unplugged program, 2) practicality of unplugged instruction, 3) productive interaction and promising feedback, and 4) independent learning and perceived perception, in accordance with the participants' perception about the unplugged instruction, material-light and conversation-driven tasks, together with the received feedback.

\section{Total Involvement in the Unplugged Program}

In contrast to control-group instruction, in the UCM instruction learners had enough time to spend on the activities that demanded more practice. The participants on the whole reported, "The instructor spent more time on the "Let it run" stage, so that we had the possibility to practice the conversations with more focus on the accuracy." Another participant, when asked "Which aspect of oral proficiency was stressed more in the classroom?" said, "The stages were orchestrated in a dynamic way so that we had the opportunity to work on the three aspects of oral proficiency".

\section{Practicality of Unplugged Instruction}

Concerns regarding the unplugged instruction were more widespread as they were distinct from the instruction recommended by the book. One participant argued, "At the beginning of the course I was afraid of losing the track of the book, but after the first unplugged session, I learned about the well-organized syllabus and since there were no limitations to learn the new concepts I felt I had learned more from the unplugged instruction than the restricted patterns of the book." 


\section{Productive Interaction and Promising Feedback}

Regarding giving the feedback on their classmates' discussions, opinions differed when learners received feedback in the "Let it run" and in the recapped practices with their partners in the "Round it off" stage. As uttered by one of the participants, "During the "Let it run" and also "Round it off" I gave and received beneficial feedback as I experienced natural communication."

\section{Independent Learning and Perceived Perception}

In response to the significance of unplugged instruction on learners' independent learning, one participant commented, "The best thing that I experienced in the class pertained to teacher-learner and learner-learner interactions". Regarding the issue of self-learning, another participant stated, "I loved the conversation-driven tasks in all the three stages and I learned how to communicate for different purposes."

\section{DISCUSSION AND CONCLUSION}

This study identified the significant effect of two types of non-conventional classrooms on EFL learners' oral proficiency. In the FCM, learners were responsible for running the online platform. Therefore, all of the activities before the class were effective as learners repeatedly reported positive insights towards the flipped tasks. Other flipped studies hinted to the effectiveness of flipped activities in growing responsibility among learners (Baepler et al., 2014; Boucher et al., 2013; Wu, 2016; Engin, 2014; Khan, 2011; Mason, et al., 2013; Wu et al., 2017; Zhai et al., 2017). Although the scope of this study was limited to upper-intermediate learners, the aforementioned instructions can be applicable to a multitude of learners with different proficiency levels. In other words, WhatsApp assisted learners to solve their communicative problems via collaborative tasks while learners had the opportunity to participate in real-life interaction and socialize with their classmates outside the class. In the FCM, listening to the podcasts and summarizing them in learners' words boosted learners' fluency and accuracy, whereas, learners reported that they noticed the difference in their rate of speaking. The most problematic area for the learners, as they explained, was related to the correct usage. However, the online platform was remarkably useful in which there was no time limitation for the learners to listen to the podcasts, to summarize the listening part, and to listen to their classmates' voices for giving feedback and learning from each other. Thereafter, learners' accuracy improved through online practices. Because the podcasts were selected according to the textbook's subjects and the flipped participants needed to combine their background knowledge with the received knowledge gained from the listening parts and the textbook's materials, learners enjoyed higher levels of complexity as well. These findings enhance EFL teachers' understanding of virtual learning merits including its interactive nature for conveying the meaning while being attractive at the same time. The gained results support the findings of previous studies on the usefulness of online classrooms for boosting learners' speaking ability (Wu et al., 2017), collaborative problem-solving (Bergmann \& Sams, 2012; Danker, 2015; Kunz, 2013), or even improving learners' other skills including listening, reading or writing (Afrilyasanti et al., 2016; Engin, 2014; Zhang, 2017; Zhonggen \& Wang, 2016). The 
results of this study proved that the application of social networking applications such as WhatsApp in the virtual learning community was much more effective than the unplugged conversations in the traditional classroom because the FCM learners outperformed the UCM participants and the control group students in both IELTS ${ }^{\text {TM }}$ Style Interview test and Paper-based Exam in the posttest.

Turning now to UCM, conversation-driven tasks helped learners to build dialogues and communication in small groups (Ushioda, 2011). In addition, the emergent language that the teacher used in the class was a supportive asset to scaffold authentic communication. The most obvious finding to emerge from UCM is that exposing learners to lightmaterial and in-depth conversations was more effective than teaching based on the textbooks. In contrast, it should be pinpointed that there were some problems at the early sessions of UCM including learners' fear of putting the printed materials aside and trusting the conversational practices for improving their speaking and writing skills. Previous lines of research, on the other hand, posed the same dilemmas for unplugged beginners (Banegas, 2012; Bryndal, 2014; Sketchley, 2011, 2012).

These findings suggest several courses of action for unplugged applicants in the ELT era. One possible solution to avoid learners' frustration in the early sessions of UCM is to run the unplugged classroom based on recommended stages that Meddings and Thornbury (2009) presented for unplugged instruction. It is the instructor's responsibility to set the scene for the unplugged syllabus. In the unplugged classroom, learners' individuality is the most counted matter. However, it should be recommended to unplugged teachers to pay attention to learners' emergent needs and encourage learners to participate in the group's conversations. An advantage of small groups and large groups' conversations is that learners will be aware of the communication breakdowns when they observe their classmates' mistakes. Scaffolding their classmates and learning from their partners' mistakes give them a sense of confidence and guide them to better collaboration. The UCM participants, on the other hand, pointed to the fact that the most practical stage in the classroom was the "Let it run" stage as they had enough time to practice the conversations and communicate in large groups. Unplugged participants were satisfied with the instruction as they discussed the effectiveness of inclass discussions and teacher's provoking questions in the "Set it up" stage to increase their oral proficiency in all the three dimensions. Although learners were not aware of the amount of change in their performance, most of them concurrently reported that after passing one or two sessions of unplugged classroom, they had the courage to participate in class discussions without any hesitation. More importantly, unplugged learners asserted that improving fluency and complexity were the most noticeable changes they felt in their speaking. The instructor reported positive impact of class discussions on learners' accuracy as well as speaking in higher rate and applying more difficult vocabularies.

For presenting the UCM it is highly advisable to organize a well-prepared lesson plan in order to cover the unplugged stages. To finely tune the procedures, it is recommended to build conversational tasks based on learners' background knowledge. Subsequently instead of treading on learners' toes, ask learners for collaborating with their partners 
and monitoring their classmates' practices to keep them on their toes. Unlike its name, the unplugged instruction demands a highly structured design and learners need to be plugged away at conversational tasks to enhance their oral proficiency.

The results of the CoI questionnaire to evaluate FCM and UCM participants' satisfaction from these two different instructions revealed that FCM users were more satisfied with the instruction and implementation of flipped classroom as they showed higher level of perception compared to their UCM counterparts in the unplugged classroom. Previous CALL studies on improving learners' speaking skill have not dealt with the possible gains or losses of such cutting-edge tools for Iranian learners. Moreover, very little is known about "Dogme" language teaching in the EFL context, and what is not clear yet is the impact of UCMs on Iranian EFL learners' oral proficiency. Subsequently, these findings may help teachers to discern what the negative and positive aspects of teaching unplugged in an EFL setting are and how conversation-driven zones may help or impede learners' divergent language skills. The findings of this study recommend the application of FCM for learners with lower confidence to participate in the conversations assuredly. EFL learners may and can benefit from the online platforms if the instructor implements the FCM with clear instructions and direct objectives. In other words, unless teacher and learners cooperate for building the flipped instruction, the FCM will be a complete debacle. One part of the flipped instruction should be undertaken by participants to follow the rules and to be responsible for the activities before the classroom. Through another part of the instruction, the teacher has to take the responsibility of learners' assignments in the online platform. Notwithstanding the relative small sample size, the findings indicated the usefulness of mobile-assisted language learning tools including WhatsApp and many other popular smartphone apps for creating an affective learning community for the EFL learners. Future attempts should assess the effectiveness of these non-conventional learning communities on other language skills including reading and writing for learners in divergent EFL settings.

\section{REFERENCES}

Afrilyasanti, R., Cahyono, B., \& Astuti, U. P. (2016). Effect of flipped classroom model on Indonesian EFL students' writing ability across and individual differences in learning. International Journal of English Language and Linguistics Research, 4, 6581 .

Akca, C. (2012). Dogme Unplugged. In Institute of Language and Communication Studies (ILCS) (Eds), International Symposium on Language and Communication: Research Trends and Challenges-Proceedings Book (pp. 1743-1756)

Baepler, P., Walker, J. D., \& Driessen, M. (2014). It's not about seat time: Blending, flipping, and efficiency in active learning classrooms. Computers \& Education, 78, 227 236.

Banegas, D. L. (2012). Teaching unplugged: Is Dogme an innovation or a remake. Share Convention, Buenos Aires, 26 July, 2012, 1-9. Retrieved from https://www.academia.edu/2319484/Teaching_unplugged_Is_Dogme_an_innovation_or _a_remake. 
Bergmann, J., Overmyer, J., \& Wilie, B. (2011). The flipped class: Myths vs. reality. Retrieved from The Daily Riff: http://www.thedailyriff.com/articles/the-flipped-classconversation-689.php.

Bishop, J. L., \& Verleger, M. A. (2013). The flipped classroom: A survey of the research. ASEE Annual Conference \& Exposition, Atlanta, 23-26 June, 2013, 1-18. Retrieved from https://www.asee.org/public/conferences/20/papers/6219/view.

Boucher, B., Robertson, E., Wainner, R., \& Sanders, B. (2013). " Flipping" Texas state university's physical therapist musculoskeletal curriculum: Implementation of a hybrid learning model. Journal of Physical Therapy Education, 27(3), 72-77.

Brown, H. D. (2001). Teaching by principles: An integrative approach to language pedagogy (2nd ed.). White Plains, NY: Longman.

Bryndal, M. (2014). Dogme ELT. Developing teachers. Retrieved from http://www.developingteachers.com/articles_tchtraining/dogme1_malgorzata.htm

Chen, Y., \& Wang, Y., Kinshuk, \& Chen, N. S. (2014). Is FLIP enough, 16-27.

Chong, C. J. (2016). Potential tools for blended learning in mathematics courses. A Bulletin of National Higher Education Research, 4-5.

Engin, M. (2014). Extending the flipped classroom model: Developing second language writing skills through student-created digital videos. Journal of the Scholarship of Teaching and Learning, 14(5), 12-26.

Folse, K. S. K. S. (2006). The art of teaching speaking: Research and pedagogy for the ESL/EFL classroom (No. Sirsi) i9780472031658).

Hayes, A. F., \& Krippendorff, K. (2007). Answering the call for a standard reliability measure for coding data. Communication Methods and Measures, 1, 77-89.

Huelskamp, D. (2015). Flipping the collegiate science classroom: A review of the research. Global Education Journal, 2015(1), 61-72.

Hung, H. T. (2017). Design-Based Research: Redesign of an English Language Course Using a Flipped Classroom Approach. TESOL Quarterly, 51(1), 180-192.

Joanne, C. S. M., \& Lateef, F. (2014). Validating "Look, Listen, Feel" for practical communications in the Emergency Department. Journal of Acute Disease, 3(4), 277283.

Khan, S. (2011). Let's use videos to reinvent education. TED Lectures. Retrieved from TED website:

http://www.ted.com/talks/salman_khan_let_s_use_video_to_reinvent_education.html.

Mason, G. S., Shuman, T. R., \& Cook, K. E. (2013). Comparing the effectiveness of an inverted classroom to a traditional classroom in an upper-division engineering course. IEEE Transactions on Education, 56(4), 430-435.

Meddings, L. (2015). Twenty steps to teaching unplugged. British Council English and Exams [Video file]. Retrieved from https://www.youtube.com/watch?v=ydWvzbWI83g 
Meddings, L., \& Thornbury, S. (2009). Teaching unplugged. Dogme in English Language Teaching. Delta Teacher Development Series. Delta.

Overmyer, G. R. (2014). The flipped classroom model for college algebra: Effects on student achievement (Doctoral dissertation, Colorado State University).

Richards, J. C., \& Bohlke, D. (2012a). Four corners 1 with self-study CD-ROM. Cambridge University Press.

Richards, J. C., \& Bohlke, D. (2012b). Speak Now 1-Communicate with. Oxford.

Richards, J. C., \& Schmidt, R. (eds.) (2002). Dictionary of language teaching and applied linguistics (3rd ed.) Harlow: Longman.

Roshan, S. (2013). With flipped learning, how to make sure students are doing the work. Retrieved from https://www.eschoolnews.com/2013/06/10/with-flipped-learning-howto-make-sure-students-are-doing-the-work/.

Sketchley, M. (2011). An investigation into teacher and student attitudes of the key tenets of Dogme ELT (Doctoral dissertation, MA dissertation). Retrieved 12th March, 2012 from http://www.scribd.com/doc/83684117/Dogme-ELT-Dissertation-FinalVersion).

Sketchley, M. (2012). Learning one-to-one. Learning one-to-one. Cambridge University Press 2010, £ 23.4. ISBN 978052113458 3. Journal of Second Language Teaching \& Research, 1(1), 92-95.

Thornbury, S. (2001). Teaching Unplugged. It's for Teachers.

Thornbury, S. (2002). Training in instructional conversation. Language in language teacher education, 4, 95-106

Thornbury, S. (2005). How to teach speaking. Longman.

Thornbury, S. (2017). Scott Thornbury's 30 language teaching methods google ebook: Cambridge handbooks for language teachers. Cambridge University Press.

Thornbury, S., \& Slade, D. M. (2006). Conversation: From description to pedagogy.

Vygotsky, L. (1978). Interaction between learning and development. Readings on the development of children, 23(3), 34-41.

Vygotsky, L. (1987). The collected works of L. S. Vygotsky, volume 1. Problems of general psychology. R. Reiber \& A. Carton (Eds.), New York: Plenum Press.

$\mathrm{Wu}$, Y. (2016). Factors impacting students' online learning experience in a learner-centred course. Journal of Computer Assisted Learning, 32(5), 416-429.

Wu, W. C. V., Hsieh, J. S. C., \& Yang, J. C. (2017). Creating an online learning community in a flipped classroom to enhance EFL learners' oral proficiency. Journal of Educational Technology \& Society, 20(2), 142-157.

Xerri, D. (2012). Experimenting with Dogme in a mainstream ESL context. English Language Teaching, 5(9), 59-65. 
Zhai, X., Gu, J., Liu, H., Liang, J. C., \& Chin-Chung, T. (2017). An experiential learning perspective on students' satisfaction model in a flipped classroom context. Journal of Educational Technology \& Society, 20(1), 198.

Zhang, F. (2016). Outline signal teaching method and college English reading teaching under the environment of MOOC. Paper presented at the AMAHS International Conference. https://doi.org/10.2991/amahs-16.2016.97

Zhang, F. (2017). Quality-improving strategies of college English teaching based on microlesson and flipped classroom. English Language Teaching, 10(5), 243.

Zhonggen, Y., \& Wang, G. (2016). Academic achievements and satisfaction of the clicker-aided flipped business English writing class. Journal of Educational Technology \& Society, 19(2), 298. 